Article

\title{
Modeling and Efficiency Optimization of Steam Boilers by Employing Neural Networks and Response-Surface Method (RSM)
}

\author{
Heydar Maddah ${ }^{1}$, Milad Sadeghzadeh ${ }^{2}{ }^{(D}$, Mohammad Hossein Ahmadi $^{3}$, Ravinder Kumar ${ }^{4}$ \\ and Shahaboddin Shamshirband $5,6, *$ (D) \\ 1 Department of Chemistry, Payame Noor University (PNU), P.O. Box, Tehran 19395-3697, Iran \\ 2 Department of Renewable Energy and Environmental Engineering, University of Tehran, \\ Tehran 1417853933, Iran \\ 3 Faculty of Mechanical Engineering, Shahrood University of Technology, Shahrood 3619995161, Iran \\ 4 School of Mechanical Engineering, Lovely Professional University, Phagwara 144411, India \\ 5 Department for Management of Science and Technology Development, Ton Duc Thang University, \\ Ho Chi Minh City, Vietnam \\ 6 Faculty of Information Technology, Ton Duc Thang University, Ho Chi Minh City, Vietnam \\ * Correspondence: Shahaboddin.shamshirband@tdtu.edu.vn
}

Received: 6 June 2019; Accepted: 3 July 2019; Published: 15 July 2019

\begin{abstract}
Boiler efficiency is called to some extent of total thermal energy which can be recovered from the fuel. Boiler efficiency losses are due to four major factors: Dry gas flux, the latent heat of steam in the flue gas, the combustion loss or the loss of unburned fuel, and radiation and convection losses. In this research, the thermal behavior of boilers in gas refinery facilities is studied and their efficiency and their losses are calculated. The main part of this research is comprised of analyzing the effect of various parameters on efficiency such as excess air, fuel moisture, air humidity, fuel and air temperature, the temperature of combustion gases, and thermal value of the fuel. Based on the obtained results, it is possible to analyze and make recommendations for optimizing boilers in the gas refinery complex using response-surface method (RSM).
\end{abstract}

Keywords: modeling; optimization; steam boiler; neural network; response-surface

\section{Introduction}

Steam boilers are designed to supply steam for heat transfer purposes due to considerable latent heat value [1,2]. Steam is the main feed of several industries in case of direct or indirect utilization since the heat transfer coefficient of steam is two times more than water. Therefore, it can be utilized effectively in power production plants in order to generate electricity [3,4]. Thus, the boiler considered as the most significant component in power plants, refineries, and so forth $[5,6]$. The working conditions of a boiler should be always monitored. It must be highlighted that boilers are working under high temperature and pressurized status, hence explosion is a serious risk, which is threatening in boiler operations $[7,8]$. In the design procedure of the boilers, several aspects, including financial, fuel cost, and maintenance factors should be covered and noticed. The complexity of the steam boiler makes it challenging to perform common measurements since several factors affect the performance of the boiler. Traditional evaluation methods of boiler performance are neither cost-effective nor time-saving [9,10]. Besides, to carry out a comprehensive, accurate analysis, the fuel composition should be analyzed before and after the combustion process in detail [11,12].

The earlier studies on heat transfer and boiling were carried out by researchers such as Gongur and Winterton [13] and Kandlikar [14]. The researchers collected a large amount of laboratory data by 
conducting several experiments. They achieved to present some correlations that could be employed to estimate the boiling behavior with little error. In the current time, computational fluid dynamic (CFD) methods have been used extensively to investigate the boiling regime and its associated involved mechanisms. Judd and Hwang [15] proposed a model for the prediction of boiling heat, which includes evaporation and natural heat transfer mechanisms. They found that the evaporation heat transfer is a significant proportion of the total heat transfer. The application of various CFD models for forced boiling simulation were studied by several researchers [16-20]. Various two-phase models with different simulation approaches employed. In these studies, the conservation equations for mass, momentum, and energy for each dissolved phase have been used. Additionally, a series of empirical auxiliary relationships were utilized in the simulation procedure. Krepper et al. [21] provided a model for the evaluation of the boiling mechanism. They investigated boiling in critical thermal flux conditions. In their research, essential parameters such as rotation, cross-flow between adjacent channels and bubble concentration regions were determined. By calculating the temperature of the bar surface, critical areas were identified, and different geometries were evaluated through CFD modeling. Rivera and Xicale [22] performed experimental evaluation and analytical assessment on an upstream flow of water-lithium bromide in a uniform vertical heated tube and provided valuable laboratory data for the saturated nucleate boiling heat transfer coefficients. Owhaib et al. [23] experimentally and analytically investigated a flow of R-134a fluid in a quartz vertical circular tube which was uniformly heated by a heater. Their primary purpose was to simulate the saturated and subcooled boiling of the rising refrigerant in the vertical pipe through the pressurized steam that was flowed out of the pipe. Stevanovic et al. [24] provided a single-dimensional multifluid model to predict two-phase flow patterns in vertical pipes. The presented model was based on the conservation of mass, energy, and momentum and was applicable to any fluid flow that has two-phase flow patterns. Yang et al. [25] presented numerical simulations and practical experiments for modeling the behavior of the R-141b refrigerant in a horizontal coil based on the fluid volume method and considering the multiphase flow model. There was a good agreement between the numerical predictions of phase change with their laboratory data. Kouhikamali [26] developed a numerical simulation for condensation in a vertical cylinder under the forced convection regime. Condensation simulations were carried out using fluid volume model and the effects of parameters such as hydraulic diameter, fluid velocity, Reynolds number, wall temperature difference, and fluid saturation temperature on heat transfer coefficient were investigated. Ozawa et al. [27] examined a range of thermal behaviors, including boiling patterns, heat transfer, pressure drop, and critical thermal flux during high-pressure carbon dioxide boiling for a horizontal microwave channel. The studied variables were tube diameter changes, mass flux, wall thermal flux, and saturation temperature and pressure of the fluid. Saisorn et al. [28] examined the R-134a refrigerant evaporation flow through horizontal and vertical mini channels in order to obtain heat transfer data and also simulation and determination of fluid flow patterns. Dimensions of the fixed tube were considered to be constant, and the parameters of the thermal flux, mass flux, and the saturation pressure of the inlet fluid were analyzed to determine the flow of fluid in two horizontal and upward flow conditions. Shen et al. [29] studied a downward fluid flow in a vertical tube for a wide range of parameters such as pressure, mass flux, and thermal flux. Water considered as the working fluid, and the thermal distribution diagram was plotted near the tube wall. In the following study, the effect of the thermal flux of the wall on the heat transfer coefficient and wall temperature were investigated, new experimental correlations were presented, and the heat transfer coefficient was compared in a downstream current with a rising flow.

Chen et al. [30] investigated the engineering applications of constructal theory in China. Xie et al. [31] applied constructal theory to optimize heat transfer performance and pressure drop of an evaporator boiler. Behbahaninia et al. [32] presented a novel auditing approach to monitor the performance of steam boilers based on exergy approach. This method was proposed based on ASME PTC (Performance Test Code Standards) 4.1 to calculate the exergy loss and exergy efficiency. Some significant factors included exergy destruction inside the boiler, exergy loss in the wall of the boiler, exergy destruction in the gas-air heater, 
exergy loss in the flue gas. It concluded that the major irreversibility of the boiler is due to inside exergy destruction, i.e., more than $38 \%$. In addition, the total exergy efficiency of the boiler was calculated by $53.7 \%$. Li et al. [33] investigated the performance of a boiler in a biomass energy production plant and used the exergy method. It was reported that the most irreversibilities originated from the combustion process. It was found that the total exergy efficiency of the boiler could be increased by decreasing the excess air and by augmenting the superheater temperature. Li, et al. [34] compared various scenarios in order to prevent the inefficient working of a boiler in a $660 \mathrm{MW}$ coal power plant. The authors recommended that the approach of closing part of the 2nd air nozzle was the most beneficial approach among other studied methods. In another study, Li et al. [35] analyzed the effect of increasing primary air ratio on the performance of a boiler in a coal-fired power plant. It was monitored that increasing the primary air temperature was more practical and also improved the thermal performance of the boiler instead of increasing the air ratio. Javan et al. [36] performed an exergoeconomic optimization of a gas-fired steam power plant by applying a genetic algorithm. Based on the results, the boiler was the most exergy-destructive source in the power plant. Therefore, two approaches are presented and compared to decrease the amount of exergy destruction in the boiler in order to improve the total efficiency of the power plant: Reducing the amount of excess air and decreasing the outlet temperature of the boiler's exhaust gas through heat recovery approaches. It was stated that this optimization technique was able to lower the total cost rate by $20 \%$ and decreased the dangerous environmental impact by $88 \%$. Pattanayak et al. [37] optimized the soot blowing frequency of a boiler in a coal-fired power plant in order to lower the hazardous combustion emission and increase the boiler's efficiency. Sobota [38] proposed an on-line monitoring method to improve the efficiency of a steam boiler. Nikula et al. [39] proposed a data-driven model to estimate and monitor the thermal performance of the boiler in order to achieve a higher efficiency boiler with a reduction in emission pollutants. Vandani et al. [40] used a genetic algorithm and partial swarm optimization techniques to improve the exergetic efficiency of boiler blowdown. It was stated that outlet pressure and outlet temperature of the boiler played a significant role in improving the exergy efficiency.

In this research, the modeling of boiler efficiency was performed based on experimental data and response-surface method (RSM). Steam flow rate and output temperature were selected as independent variables. The dependent variable is considered as the boiler efficiency.

\section{Modeling Fundamentals}

Neural network approaches are magnificently powerful in the modeling of engineering applications [4144]. The neural network model is a data-driven model, so it requires experimental data to build the model $[45,46]$. In this study, with the help of the neural network modeling, the target output is predicted through two input data sets. Figure 1 illustrates the upper and lower limit of input and output data.

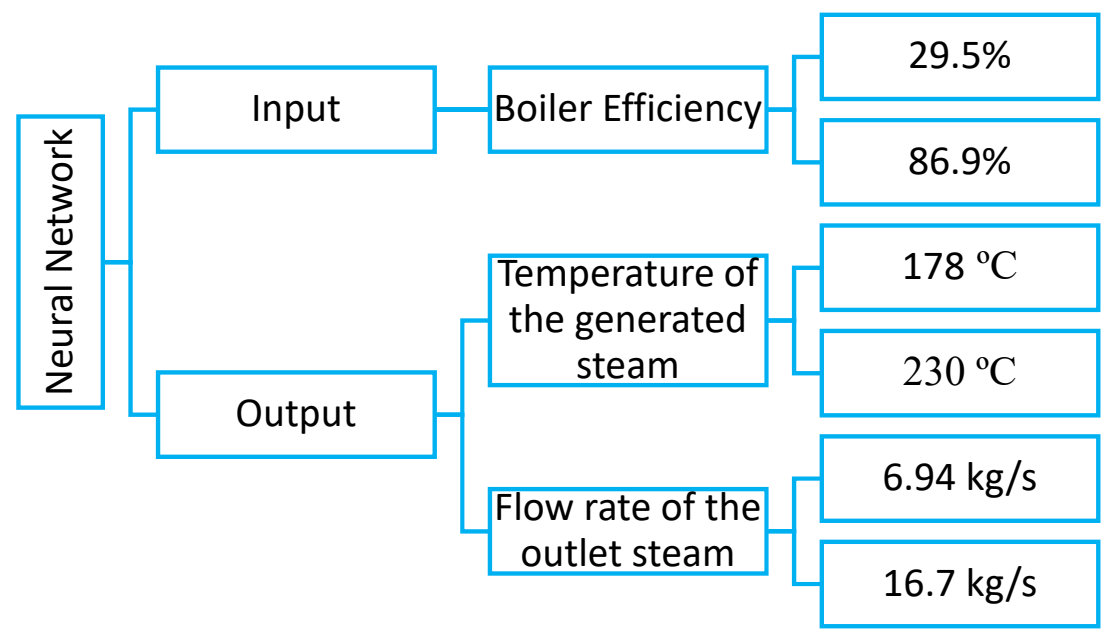

Figure 1. The upper and lower limit of input and output data for the construction of a neural network model. 
The utilized input data in the neural network modeling process is listed in Table 1 . Where, $\dot{m}$ represents the mass flow rate $(\mathrm{kg} / \mathrm{s}), T$ is the temperature $\left({ }^{\circ} \mathrm{C}\right)$, and $\eta$ states the boiler efficiency.

Table 1. The experimental data used to form the neural network model.

\begin{tabular}{|c|c|c|c|c|c|}
\hline$\dot{m}$ & $T\left({ }^{\circ} \mathrm{C}\right)$ & $\eta$ & $\dot{m}$ & $T\left({ }^{\circ} \mathrm{C}\right)$ & $\eta$ \\
\hline 5.06277 & 179.8114 & 68.8229 & 10.3826 & 202.5607 & 68.3157 \\
\hline 11.50799 & 217.4076 & 68.10162 & 8.112843 & 195.3354 & 66.59289 \\
\hline 10.96721 & 227.7698 & 66.7485 & 12.47747 & 228.7439 & 66.83186 \\
\hline 11.83226 & 195.8293 & 69.17249 & 15.45171 & 206.8831 & 69.76082 \\
\hline 8.164 & 211.1887 & 66.49393 & 10.33337 & 222.0078 & 66.69333 \\
\hline 8.230552 & 195.8363 & 67.13933 & 7.35201 & 199.2193 & 66.00094 \\
\hline 15.4074 & 189.2565 & 69.76787 & 8.328303 & 202.0249 & 67.16067 \\
\hline 12.80646 & 218.8824 & 68.03788 & 7.689097 & 220.9679 & 65.33974 \\
\hline 9.523767 & 215.6007 & 67.21874 & 14.14401 & 229.5426 & 67.54719 \\
\hline 15.35225 & 192.4996 & 69.97655 & 11.38288 & 205.2453 & 68.95443 \\
\hline 7.509398 & 208.2864 & 66.27828 & 13.44131 & 226.1227 & 67.40915 \\
\hline 11.39483 & 199.8923 & 68.57542 & 13.74267 & 216.4291 & 68.86722 \\
\hline 13.96593 & 182.7876 & 68.82806 & 12.49931 & 207.5064 & 68.88944 \\
\hline 10.24027 & 179.2494 & 67.70906 & 13.05674 & 228.3764 & 67.44843 \\
\hline 10.84519 & 203.5396 & 68.7183 & 15.47826 & 220.874 & 68.30319 \\
\hline 12.06786 & 192.4699 & 69.16695 & 13.38398 & 227.8997 & 67.56851 \\
\hline 15.6384 & 195.6674 & 69.49326 & 15.45541 & 211.61 & 69.13087 \\
\hline 14.51184 & 192.9422 & 69.69088 & 11.48975 & 197.7378 & 69.29713 \\
\hline 7.618852 & 186.887 & 66.61787 & 8.318545 & 202.7819 & 66.87618 \\
\hline 9.65485 & 198.7617 & 68.26366 & 7.606863 & 225.4183 & 64.83067 \\
\hline 10.63276 & 214.2778 & 67.86751 & 13.88847 & 178.7724 & 69.11839 \\
\hline 15.35098 & 188.5912 & 69.38854 & 9.938753 & 186.1481 & 67.56152 \\
\hline 11.02739 & 212.649 & 68.18121 & 13.46965 & 202.5215 & 69.66543 \\
\hline 9.276587 & 201.0394 & 67.34079 & 13.28742 & 206.2356 & 69.53684 \\
\hline 12.75497 & 200.5314 & 69.42711 & 12.10742 & 181.1039 & 68.71523 \\
\hline 11.60532 & 187.1125 & 68.66235 & 13.89687 & 212.2176 & 68.83852 \\
\hline 15.68032 & 188.0465 & 69.69601 & 11.85233 & 224.261 & 67.02746 \\
\hline 16.0319 & 210.0539 & 69.16832 & 11.68888 & 183.7009 & 68.7909 \\
\hline 14.89612 & 191.9886 & 69.48701 & 11.78454 & 200.7642 & 69.38998 \\
\hline 13.83662 & 207.1033 & 69.35699 & 16.04421 & 192.572 & 69.86828 \\
\hline 14.1702 & 227.1288 & 67.70859 & 10.72913 & 229.2328 & 66.56324 \\
\hline 15.69162 & 215.1525 & 68.53946 & 8.083356 & 209.6555 & 66.52948 \\
\hline 7.57872 & 213.3194 & 65.88433 & 9.281896 & 191.195 & 67.60546 \\
\hline 10.21025 & 227.8878 & 65.96942 & 13.60328 & 184.896 & 68.9027 \\
\hline 6.986591 & 218.3174 & 65.18013 & 15.10385 & 206.3403 & 69.70184 \\
\hline 14.99537 & 209.6018 & 69.78638 & 16.37641 & 221.0458 & 68.45829 \\
\hline 11.87784 & 227.2961 & 66.81758 & 9.036371 & 221.5243 & 66.38769 \\
\hline 10.50436 & 181.1014 & 67.63481 & 14.33667 & 221.3341 & 68.1886 \\
\hline 9.147886 & 191.973 & 67.25517 & 12.62322 & 188.5932 & 69.35013 \\
\hline 12.1442 & 229.3074 & 67.04037 & 10.86203 & 206.3097 & 68.49007 \\
\hline 9.758881 & 218.1548 & 67.08144 & 11.90317 & 223.497 & 67.82707 \\
\hline 7.609162 & 202.7184 & 66.5345 & 11.76321 & 184.292 & 68.53394 \\
\hline 7.770549 & 213.4068 & 65.85192 & 13.27719 & 222.5302 & 67.67154 \\
\hline 7.608856 & 199.6806 & 66.64859 & 14.17492 & 224.7884 & 67.86074 \\
\hline 10.92877 & 197.7678 & 68.71765 & 9.880103 & 189.329 & 67.77672 \\
\hline 8.143986 & 189.0901 & 66.894 & 7.815672 & 182.0029 & 66.12302 \\
\hline 11.25155 & 197.9128 & 69.15146 & 14.97466 & 202.6592 & 69.45441 \\
\hline 15.68414 & 179.5427 & 68.899 & & & \\
\hline
\end{tabular}


Input and output data in an artificial neural network are divided into three categories of training, validating, and testing, as demonstrated in Figure 2. Training data is used to create a model. The validation data is used to check the quality and correctness of the training stage. Test data is not used in the training phase and is used only for performance evaluation and examining the neural network modeling.

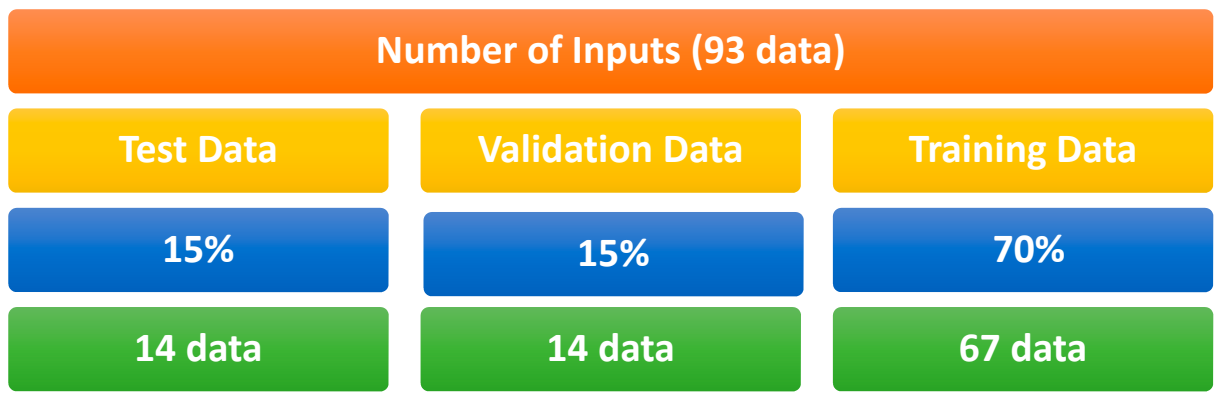

Figure 2. Randomized classification of empirical data in order to construct a neural network model.

The neural network is expressed on the basis of a particular topology. The topology introduces the structure of the network. In this investigation, a triple layer neural network, Figure 3, is used to predict the output variable, the boiler efficiency. A sample 2-5-1 structure is depicted in Figure 4. As can be seen, the number of neurons in the first, second, and third layers is 2, 5, and 1, respectively. The number of neurons in the second layer, known as the hidden layer, is arbitrary. In this research, five neurons were determined to be placed in the hidden layer. The selection of the neurons' number in the first and third layers is not arbitrary and is selected based on the number of input data to the model. According to Figure 4, the neurons in each layer are connected by the edges to the neurons in the adjacent layer. These edges determine the relationship between the input and output variables by the weight coefficients assigned to them. This mathematical relation is discussed in the following.

The structure of the Neural Network

\begin{tabular}{|c|c|c|}
\hline $\begin{array}{l}\text { First layer (Input } \\
\text { layer) }\end{array}$ & $\begin{array}{l}\text { Second layer } \\
\text { (Hidden layer) }\end{array}$ & $\begin{array}{c}\text { Third layer (Output } \\
\text { layer) }\end{array}$ \\
\hline 2 Neurons & 5 Neurons & 1 Neuron \\
\hline $\begin{array}{c}\text { Steam temperature } \\
\text { and flow rate }\end{array}$ & $\begin{array}{l}\text { Arbitrary selection } \\
\text { f neuron numbers }\end{array}$ & Boiler efficiency \\
\hline
\end{tabular}

Figure 3. Triple layer neural network structure. 


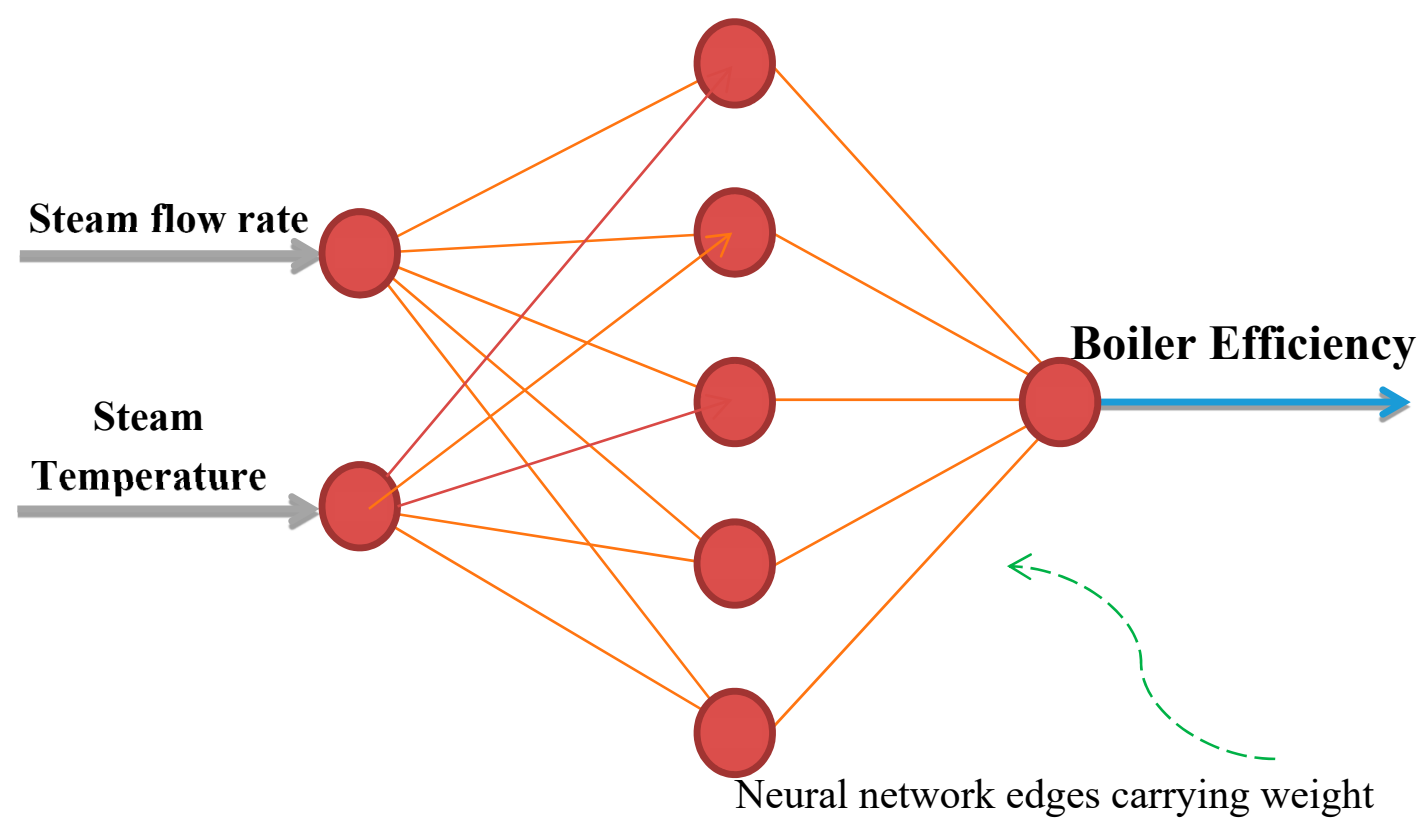

Figure 4. Sample schematic structure of a 2-5-1 neural network model: Two neurons in the input layer, five neurons in the hidden layer, and a neuron in the output layer.

The connection between input data and output data is determined by a network of linked nodes, as shown in Figure 4.

Input and output data are correlated with a series of weighted coefficients. There are $10(2 \times 5=10)$ edges between the first layer and the second layer. There are $5(5 \times 1=5)$ edges between the second layer and the third layer. Each edge is assigned a weight. The weights of these edges are presented as a $5 \times$ 2 matrix and a $5 \times 1$ matrix. The relationship between output and input data is expressed as follows:

$$
\eta=[L W]_{1 \times 5} \times \tanh \left([I W]_{5 \times 2} \times\left[\begin{array}{c}
\dot{m} \\
T
\end{array}\right]_{2 \times 1}+\left[b_{1}\right]_{5 \times 1}\right)+\left[b_{2}\right]_{1 \times 1}
$$

The employed variables in the Equation (1) are listed and defined in Table 2.

Table 2. Definition of required variables in modeling using neural network.

\begin{tabular}{|c|c|c|}
\hline Variable & Definition & Description \\
\hline$\dot{m}$ & 1st input variable & Steam mass flow rate, $\mathrm{kg} / \mathrm{s}$ \\
\hline$[I W]_{5 \times 2}$ & Edge matrix between 1st and 2nd layers & Each of the edges between layer 1 and 2 is assigned a weight \\
\hline$[L W]_{1 \times 5}$ & Edge matrix between 2 nd and 3rd layers & Each of the edges between layer 2 and 3 is assigned a weight \\
\hline$\left[b_{1}\right]_{5 \times 1}$ & Bias matrix of the 2 nd layer & $\begin{array}{l}\text { After multiplying the weight matrix in the input signal, } \\
\text { the results are summed with the bias. }\end{array}$ \\
\hline$\left[b_{2}\right]_{1 \times 1}$ & Bias matrix of the 3rd layer & $\begin{array}{l}\text { After multiplying the weight matrix in the input signal, } \\
\text { the results are summed with the bias. }\end{array}$ \\
\hline
\end{tabular}

\section{Modeling Results of Boiler Efficiency Using Neural Network}

In this section, the obtained results from the modeling by means of neural network are compared with the actual results. The total number of data used in modeling is 95 . Of these, $70 \%$ are for training, 15\% for validating, and the rest for testing the network. Figure 5 illustrates the graph error of the modeling results. The graph error is the difference between the output of the network and the actual output. 

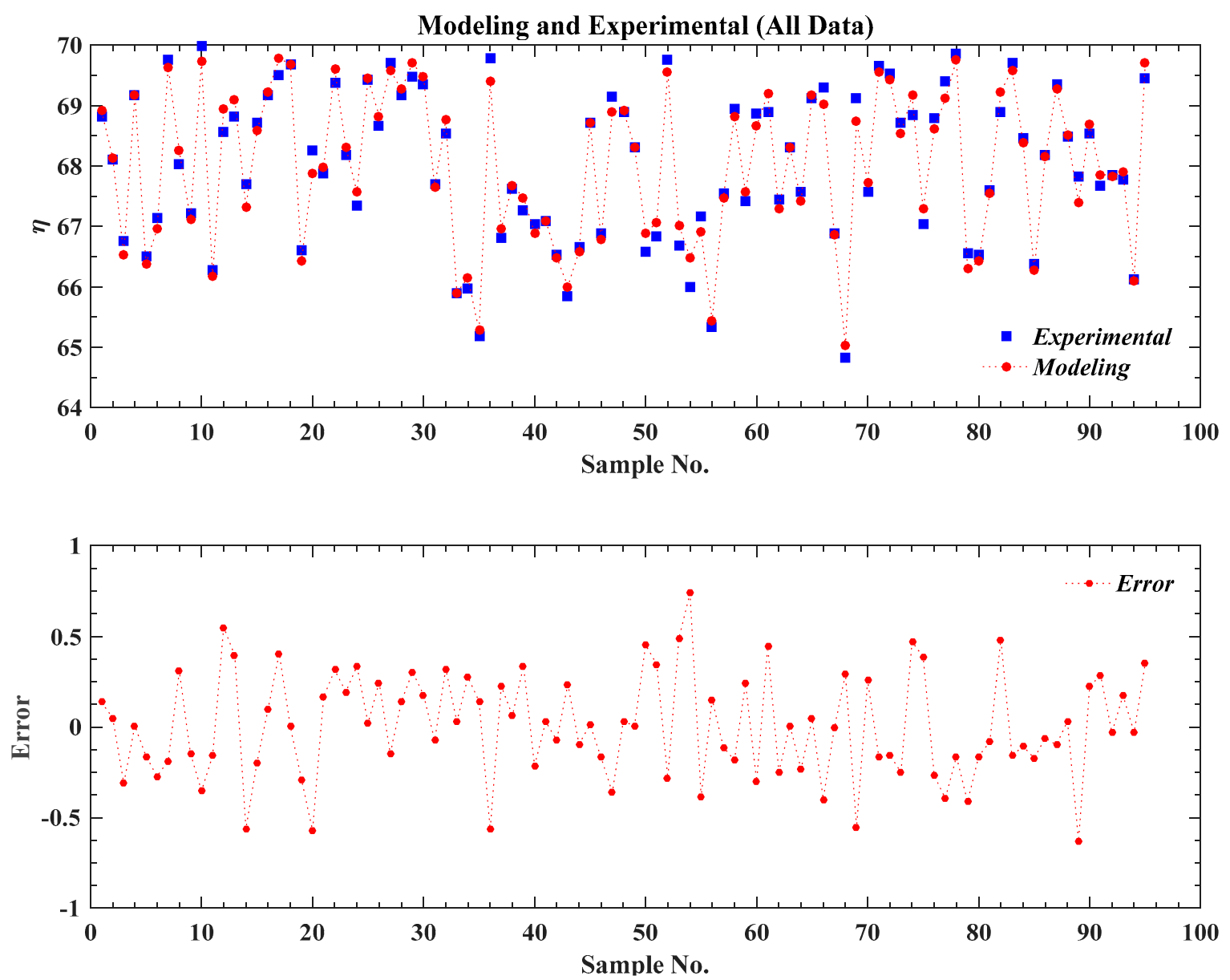

Modeling and Experimental (All data)

Figure 5. Comparison of model estimations with actual efficiency measurements (95 data).

As it is monitored, the prediction error is approximately $1 \%$ in the positive and negative range with the help of the neural network. In the following figures, the actual data (experimental) and modeling data are presented separately for each of the three categories, i.e., categories of training, validating, and testing.

Figures 6-8 demonstrate the error in the modeling data in percent for the three classes of train, validation, and test, respectively. Based on these figures, the error data for training, validating, and testing phases are obtained by $0.6,0.5$, and 1 , respectively. Test data are not involved in the training stage. Therefore, test data error is more than training and validation. 

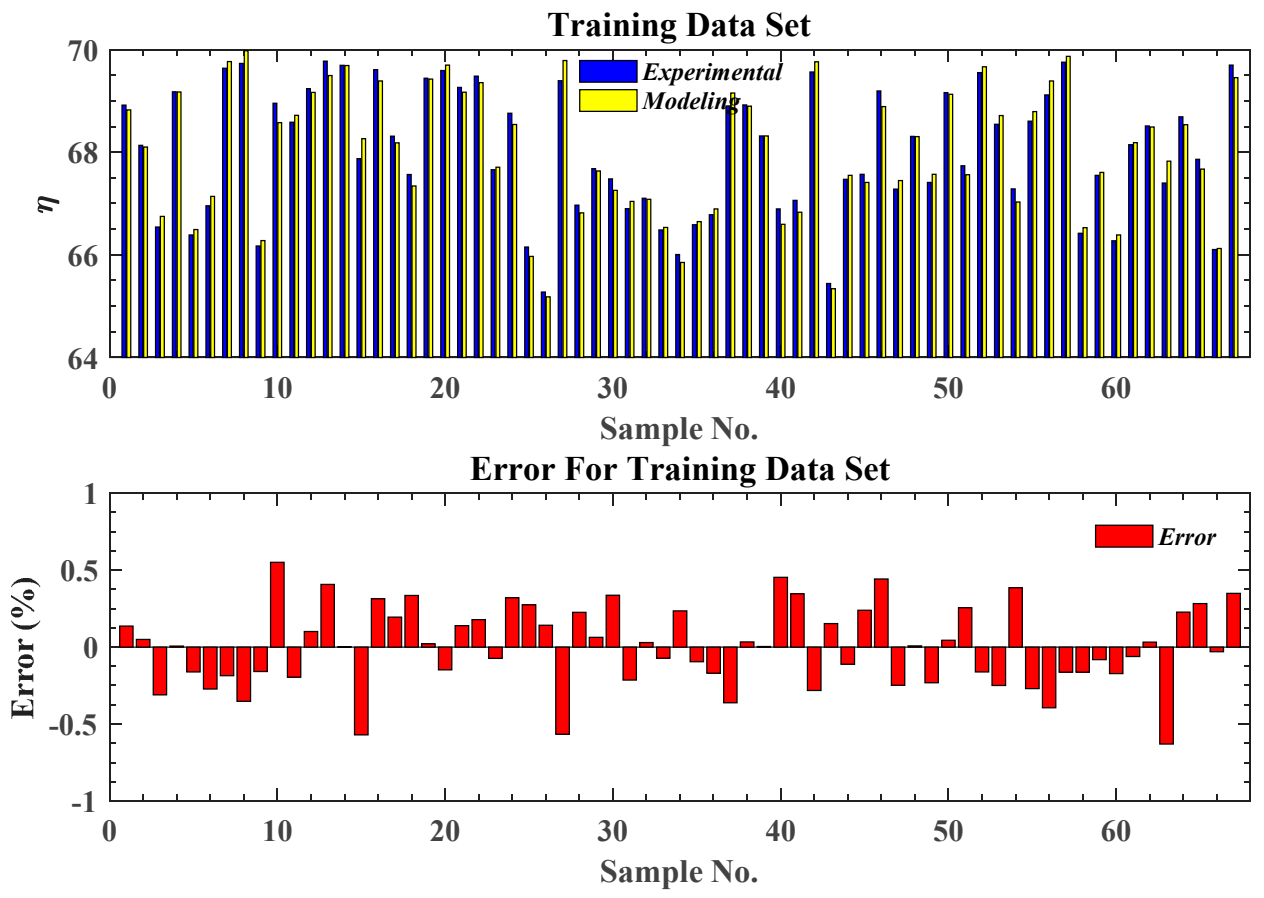

Figure 6. Comparison of experimental data and modeling for training stage (75 data).
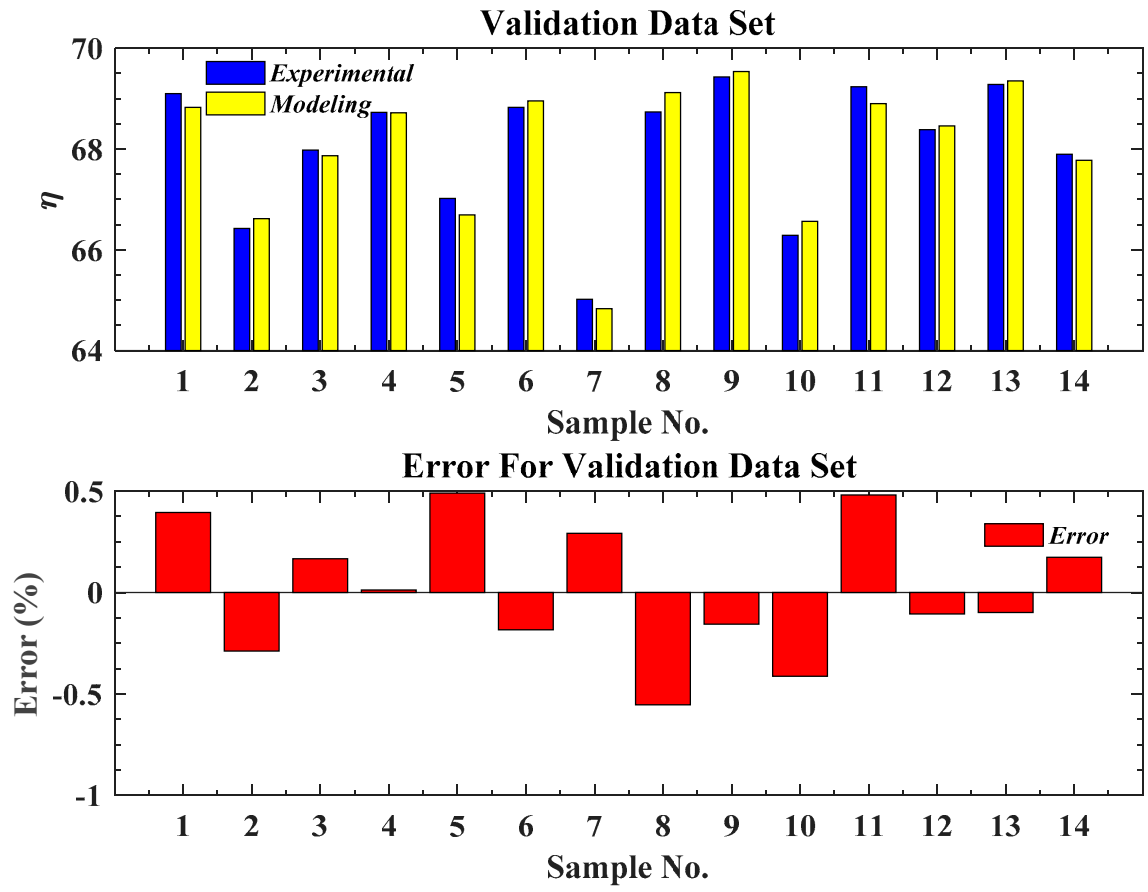

Figure 7. Comparison of experimental data and modeling for validation stage (14 data). 

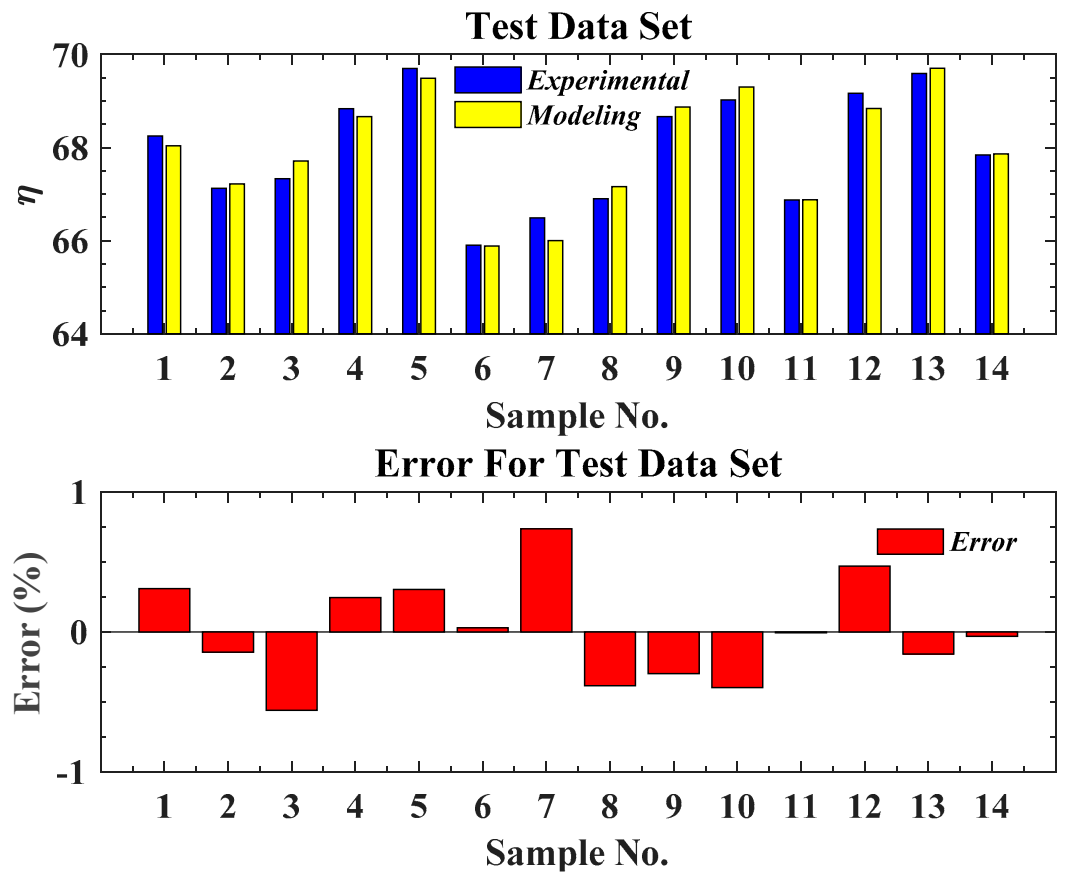

Figure 8. Comparison of experimental data and modeling for test stage (14 data).

The regression line diagram along with the mean squared error (MSE) and correlation coefficient for each of the categories of training, validation, and test are shown in Figures 9-11. As it was expected, the low error rate and high correlation coefficient indicate the proper performance of the neural network in the prediction of the boiler efficiency. In Figures 9-11, the horizontal axis is real efficiency and vertical axis demonstrates the modeling efficiency. Ideally, when the model error is zero, all points are located on the line $\mathrm{Y}=\mathrm{T}$ (first bisector quadrant line). In reality, there is a small amount of error that causes the points to be scattered up and down the line. The best-passing equation from the points in this graph along with the correlation coefficient as well as the MSE error are given in the following figures for the train, validation, and test stages.

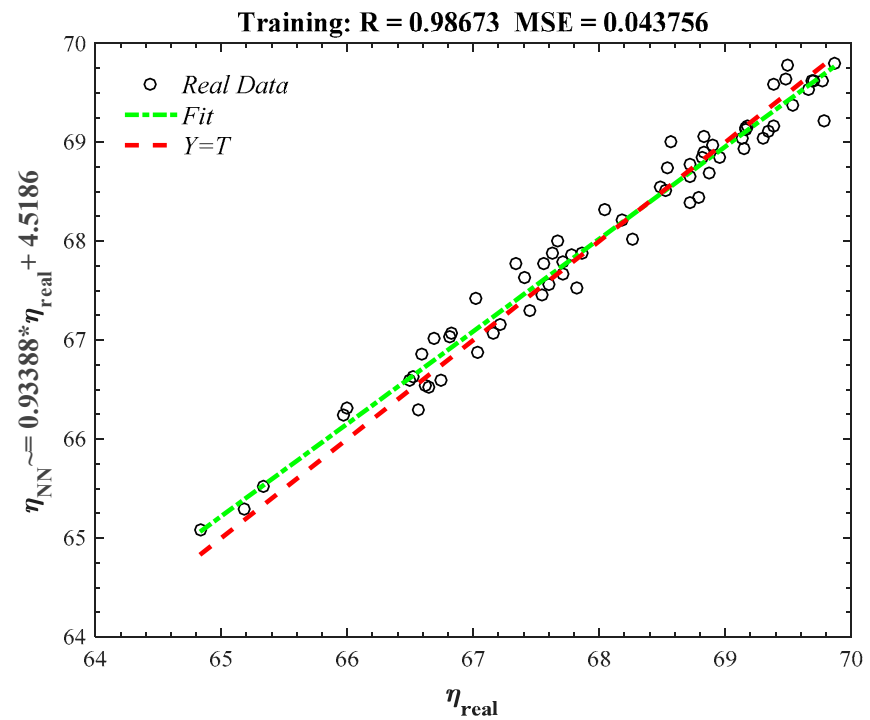

Figure 9. The regression line diagram for training data. MSE: Mean squared error. 


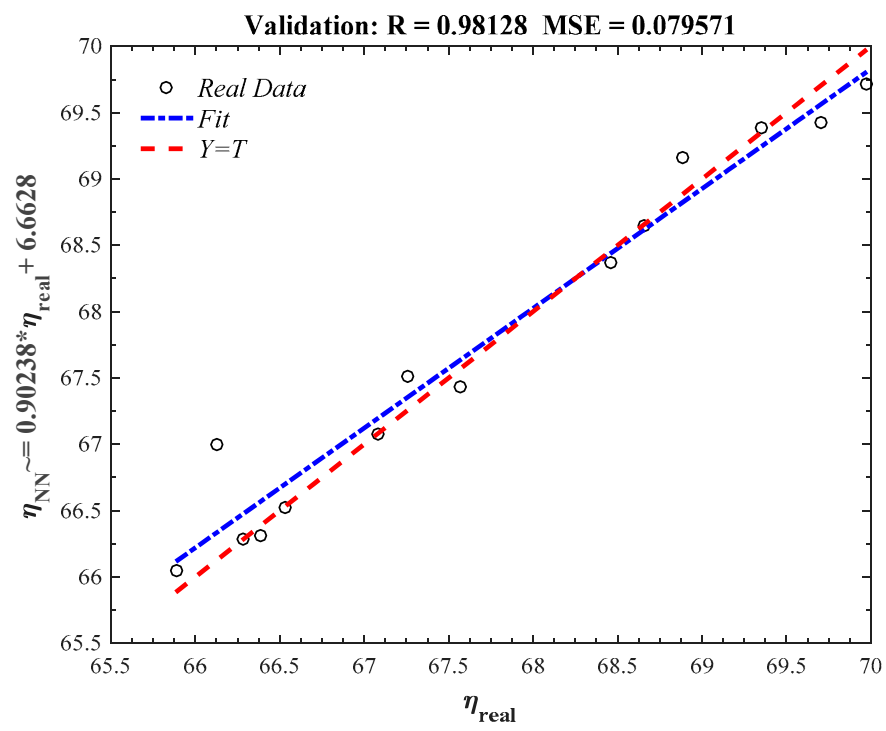

Figure 10. The regression line diagram for validation data.

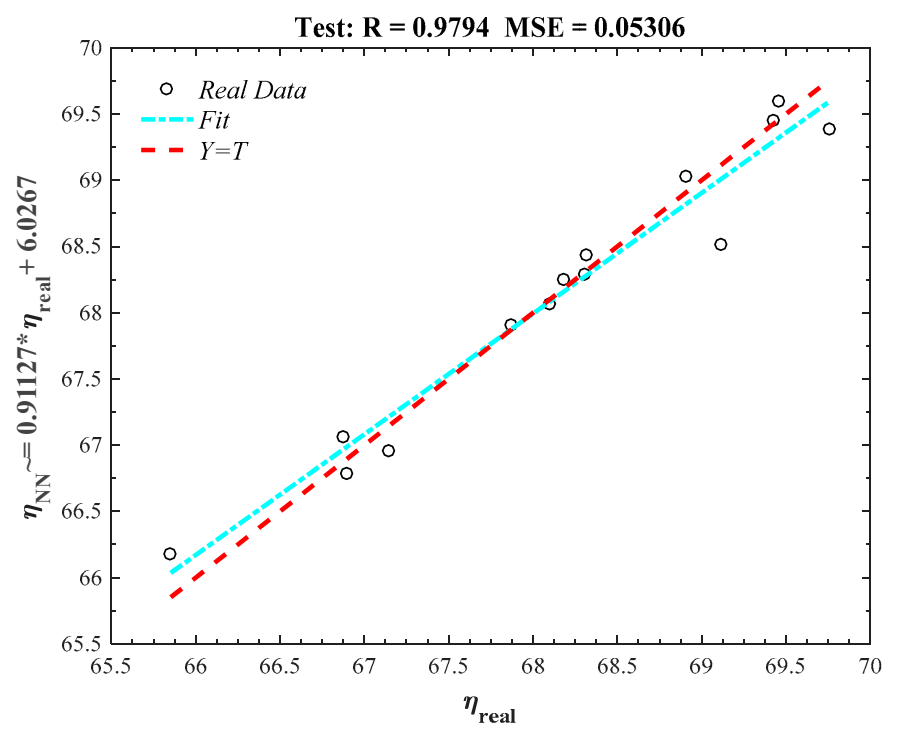

Figure 11. The regression line diagram for test data.

The network performance with respect to modeling error and regression coefficient $R^{2}$ are obtained according to Table 3.

Table 3. The performance of the neural network in predicting the efficiency.

\begin{tabular}{cccc}
\hline & Train (70\%) & Validation (15\%) & Test (15\%) \\
\hline Number of data & 67 & 14 & 14 \\
Mean squared error (MSE) & 0.043 & 0.079 & 0.053 \\
Regression coefficient $\left(\mathrm{R}^{2}\right)$ & 0.986 & 0.981 & 0.979 \\
\hline
\end{tabular}

The performance values (error and correlation coefficient) of the network are graphically depicted in Figures 12 and 13, respectively, as follows: 


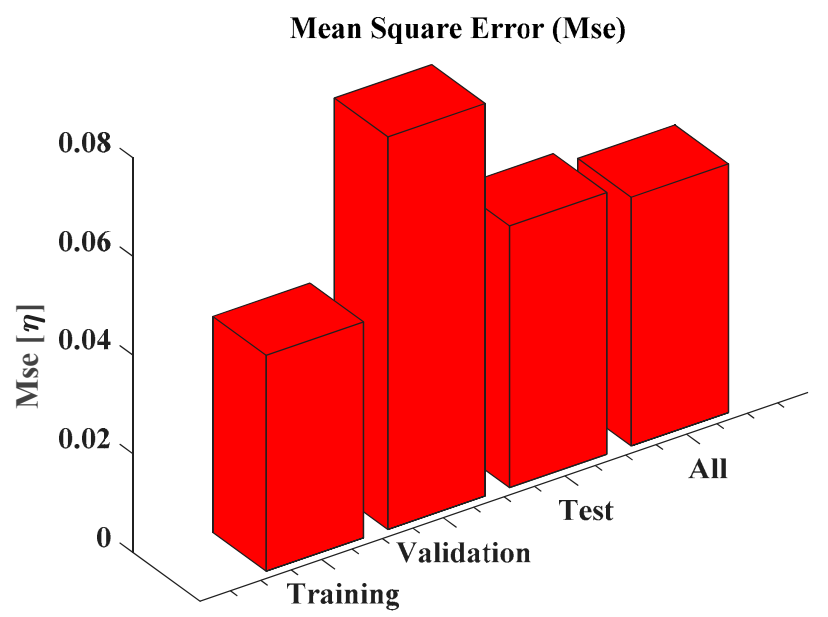

Artificial neural network model

Figure 12. Values of mean squared error (MSE) of training, validation, test, and all.

\section{Linear regression $(R)$}

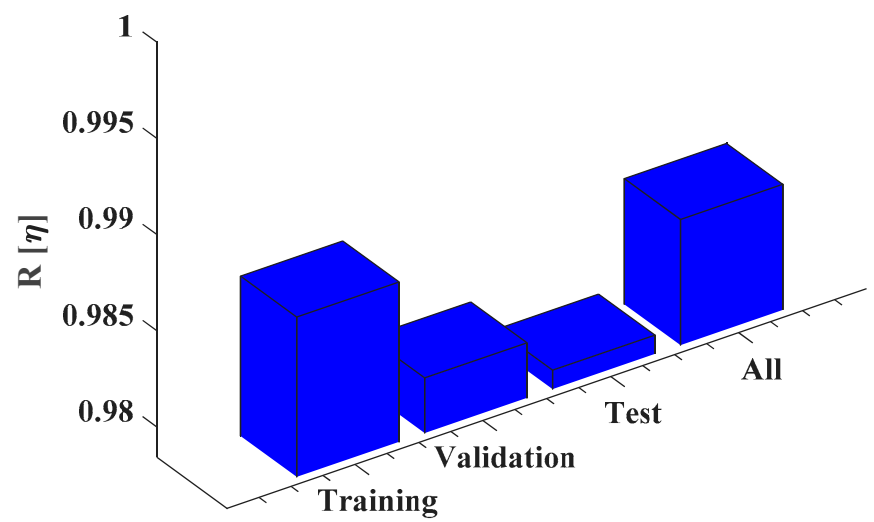

Artificial neural network model

Figure 13. The correlation coefficient of training, validation, test, and all for artificial neural network (ANN).

Most of the stopping training criteria are based on the mean square error control. Therefore, the MSE curve was plotted as a function of the repetition of the training algorithm in Figure 14.

Monitoring MSE for test data and validation data was performed in the same way as training data in various repetitions, and when the validation data error begins to increase, the training should be stopped. The most generalization occurs at the 11th epoch.

The mean square error (MSE) during the training process is demonstrated in Figure 14. Obviously, increasing the frequency led to gradually decrease in error of all three categories. With the progress of the algorithm in each repetition, the mean square error for the validation data was calculated. The algorithm does not stop until the validation error decreases, and training continues. When the validation error is not decreasing in six consecutive repetitions, the training stops. The number six is the stop training indicator, which is adjustable in the software. This number is known as the validation check and is assumed as six by default in the software.

The point where the validation error reaches its minimum is considered as the output of the model. For instance, in Figure 14 before the 11th epoch, the network error trend for the training, validation, and testing data was decreasing and from repetition 11, the verification error was increasing, while the training data error continued to decline. From Repeat 11 to Repeat 17 (six consecutive repetitions), the validation error had an increasing trend, so the training algorithm ended and Repeat No. 11 was 
considered as an output. In other words, the training was stopped if the evaluation set error was raised in six consecutive repetitions. This stop occurred at Repeat no. 11. It should be noted that the algorithm calculates the mean squared error as follows:

$$
M S E=\sum_{i=1}^{n} \frac{\left(\eta_{N N}-\eta_{\text {Real }}\right)^{2}}{N e}
$$

In Equation (2), $\eta_{N N}$ denotes the obtained modeling efficiency, $\eta_{\text {Real }}$ indicates the real measured boiler efficiency, and $\mathrm{Ne}$ represents the total number of samples.

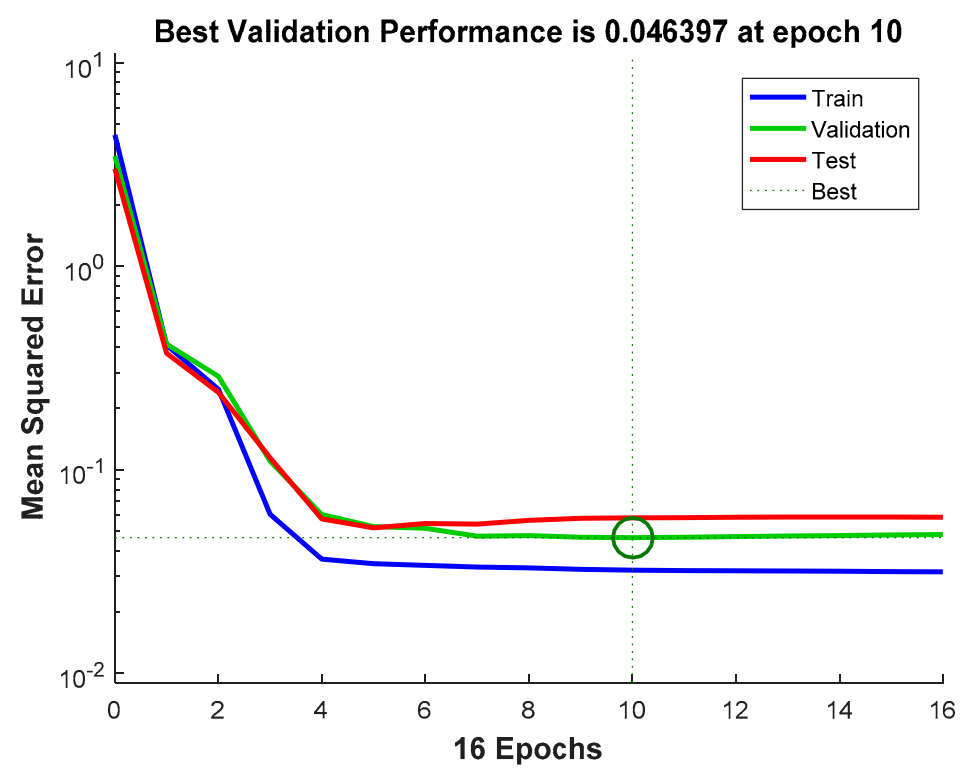

Figure 14. Mean squared error diagram in different epochs of training process for estimating the boiler efficiency.

\section{Optimization with the Help of the Response-Surface Method}

The response-surface method or RSM is a collection of statistical techniques and applied mathematics for creating empirical models. The purpose of response-surface is to optimize the response (output variable), which is influenced by several independent variables (input variables). In this study, two independent variables of flow rate and output steam temperature of the boiler, and the dependent variable of efficiency are discussed.

In Figure 15, the fitted response surface on the boiler experimental data is presented, and as can be seen, this surface is well suited with the experimental data. The constant coefficients obtained from the RSM optimization for Equation (3) are presented in Table 4.

$$
\eta(\dot{m}, T)=c_{0}+c_{1} \dot{m}+c_{2} T+c_{12} \dot{m} T+c_{11} \dot{m}^{2}+c_{22} T^{2}
$$




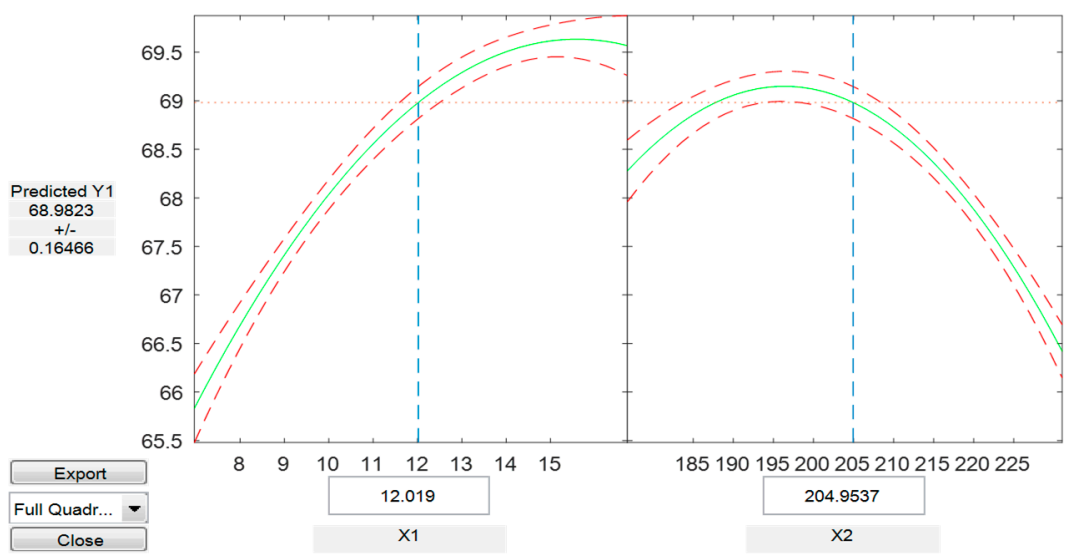

Figure 15. Response-surface method (RSM) analysis (inputs: Flow rate and temperature).

Table 4. The optimal values of the constants which are obtained by RSM optimization.

\begin{tabular}{ccccccc}
\hline Constants & C0 & C1 & C2 & C12 & C11 & C22 \\
\hline Optimized Value & -31.372 & 1.690 & 0.8977 & -0.00047 & -0.05112 & -0.00227 \\
\hline
\end{tabular}

In Figure 16, the response surface along with the experimental data is presented in a 3-D graph.

\section{Efficiency}

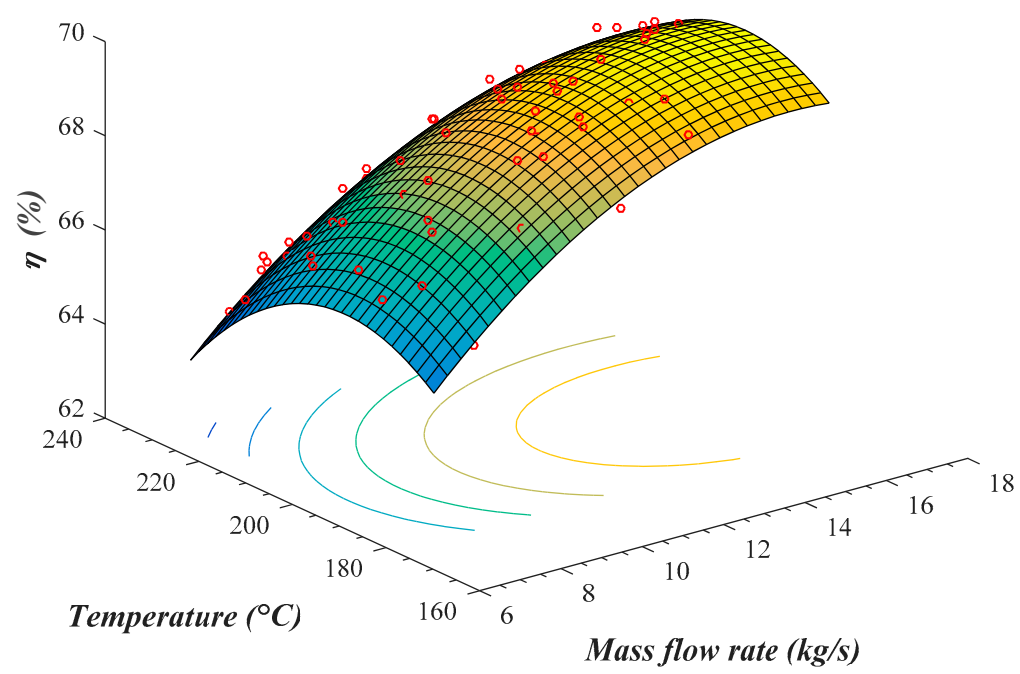

Figure 16. The fitted surface on the empirical data obtained from the boiler.

The efficiency surface has an optimal point, which is presented in Table 5 for its optimal value.

Table 5. The optimal boiler efficiency (obtained from the RSM).

\begin{tabular}{cccc}
\hline Variable & Objective Function & 1st Independent Variable & 2nd Independent Variable \\
\hline Unit & Efficiency $(\%)$ & Flow rate $(\mathrm{kg} / \mathrm{s})$ & Temperature $\left({ }^{\circ} \mathrm{C}\right)$ \\
Optimal value from RSM & 69.8 & 15.7 & 195.9 \\
\hline
\end{tabular}

\section{Sensitivity Analysis of Effecting Variables}

With the aid of sensitivity analysis, the effect of each independent variable can be obtained on dependent variables (boiler efficiency). In the sensitivity analysis, all variables were assumed to be constant 
and only one variable within its permitted range was changed. In Figure 17, sensitivity analysis was performed for the temperature variable. As can be monitored, the magnitude of the efficiency at 196 ${ }^{\circ} \mathrm{C}$ results in its maximum value for almost all flow rates. As the flow rate increases and becomes close to the designed flow rate of the boiler changes, the rate of change in efficiency will be slower in terms of temperature.

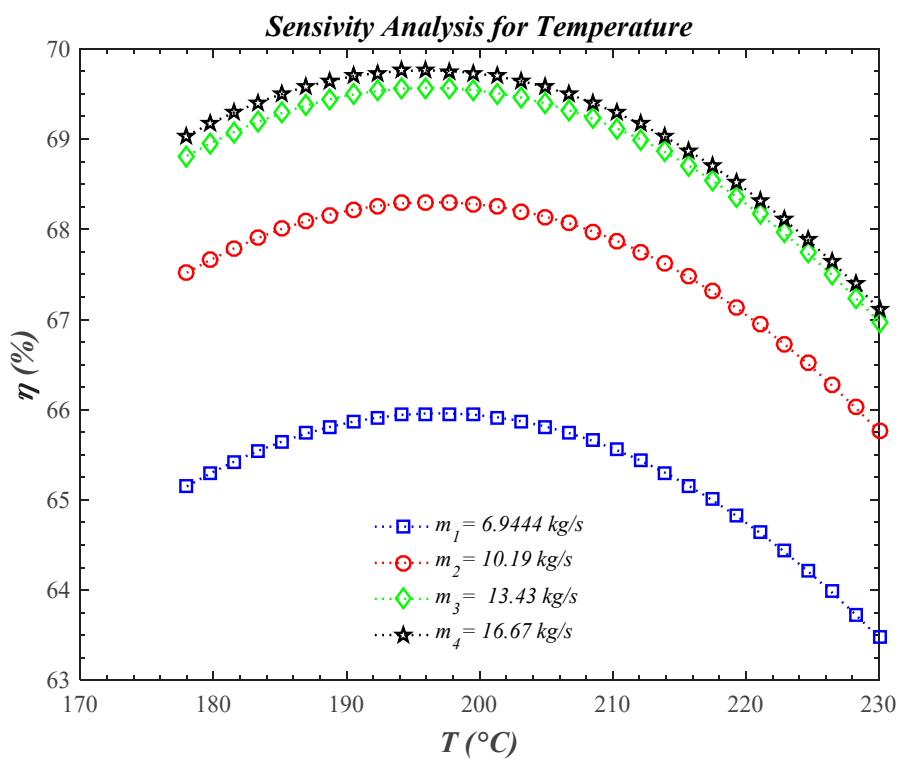

Figure 17. Temperature sensitivity analysis at four different flow rates.

Figure 18 shows the sensitivity analysis for the flow rate independent variable. As can be seen, in the flow rate of $15.7 \mathrm{~kg} / \mathrm{s}$, the amount of efficiency yielded to its maximum. With increasing temperature, first, the efficiency increases and then decreases.

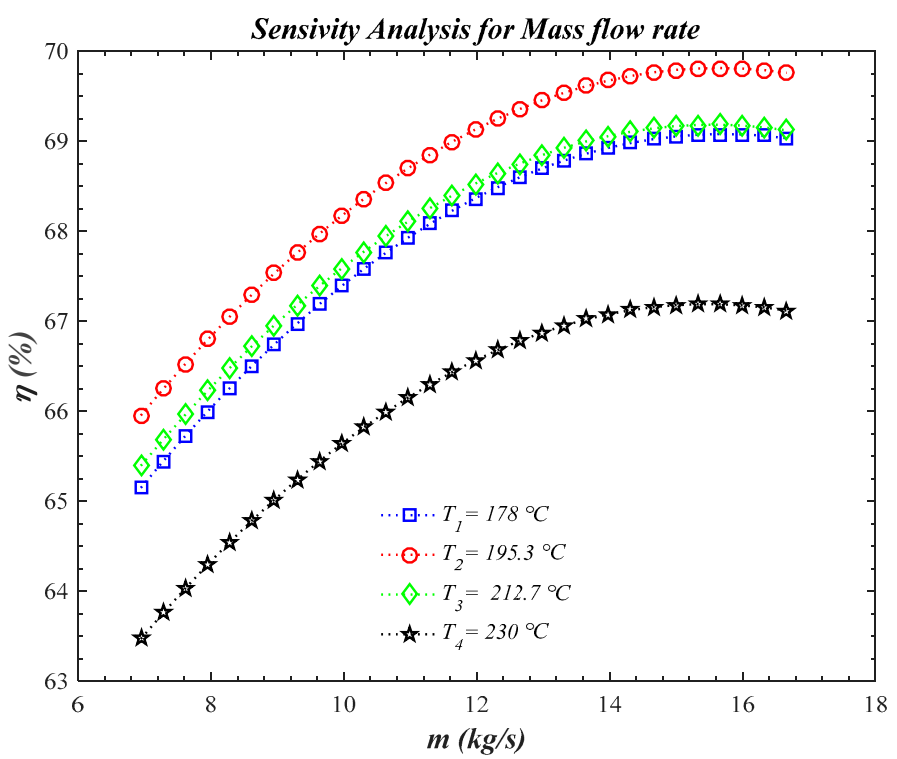

Figure 18. Flow rate sensitivity analysis at four different temperatures.

\section{Conclusions}

The plant's steam production and distribution units are designed and installed by the Iranian energy engineering company "Garmagostar" in order to provide steam and heating loads of reboilers, heaters, flares, sweetening packages, seawater treatment plant, and other steam utilities. The total 
number of data used in the modeling process was 95 which were categorized as $70 \%$ for training, $15 \%$ for validation, and the rest for the test procedure of the network. Modeling by means of neural network yields to the prediction error in the range of \pm 1 . The associated error of the training stage, validation stage, and test stage were obtained less than $0.7 \%, 0.6 \%$, and $0.8 \%$, respectively. As expected, the data test error was higher than training and validation due to the lack of participation in the test data at the training and learning stage of the neural network. In the ideal status, when the model error is zero, all points are placed on the line of $\mathrm{Y}=\mathrm{T}$ (bisection of 1st and 3rd coordination sections). In practice, there was a small amount of error that caused the points to be scattered up and down the line. The best-passing equation of the points along with the correlation coefficient as well as the mean square error were calculated for validation and test phases of the total data. Response-surface method (RSM) is a set of statistical techniques and applied mathematics for constructing empirical models. The target goal of the RSM is to optimize the response (output variable), which is influenced by several independent variables (inputs). In this study, two independent variables of steam flow rate and temperature of the generated steam and the dependent variable of efficiency are discussed. The amount of efficiency at temperatures of $196{ }^{\circ} \mathrm{C}$ resulted in maximum efficiency for almost all flow rates. As the flow rate increases and approaches the specific boiler design flow rate, the trend of variations of efficiency in term of temperature became slower. Additionally, sensitivity analysis for the flow rate variable was performed and it was monitored that the maximum amount of efficiency is yielded at the flow rate of $15.7 \mathrm{~kg} / \mathrm{s}$. With increasing temperature, first, the efficiency increases and then decreases.

Author Contributions: This work was conducted and wrote by H.M. and M.S. under the supervision of M.H.A., R.K., and S.S.

Funding: This research received no external funding.

Conflicts of Interest: The authors declare no conflicts of interest.

\section{References}

1. Echi, S.; Bouabidi, A.; Driss, Z.; Abid, M.S. CFD simulation and optimization of industrial boiler. Energy 2019, 169, 105-114. [CrossRef]

2. Ahmadi, M.H.; Alhuyi Nazari, M.; Sadeghzadeh, M.; Pourfayaz, F.; Ghazvini, M.; Ming, T.; Meyer, J.P.; Sharifpur, M. Thermodynamic and economic analysis of performance evaluation of all the thermal power plants: A review. Energy Sci. Eng. 2019, 7, 30-65. [CrossRef]

3. Szega, M.; Czyż, T. Problems of calculation the energy efficiency of a dual-fuel steam boiler fired with industrial waste gases. Energy 2019, 178, 134-144. [CrossRef]

4. Mohammadi, A.; Ashouri, M.; Ahmadi, M.H.; Bidi, M.; Sadeghzadeh, M.; Ming, T. Thermoeconomic analysis and multiobjective optimization of a combined gas turbine, steam, and organic Rankine cycle. Energy Sci. Eng. 2018, 6, 506-522. [CrossRef]

5. Hajebzadeh, H.; Ansari, A.N.M.; Niazi, S. Mathematical modeling and validation of a $320 \mathrm{MW}$ tangentially fired boiler: A case study. Appl. Therm. Eng. 2019, 146, 232-242. [CrossRef]

6. Shams Ghoreishi, S.M.; Akbari Vakilabadi, M.; Bidi, M.; Khoeini Poorfar, A.; Sadeghzadeh, M.; Ahmadi, M.H.; Ming, T. Analysis, economical and technical enhancement of an organic Rankine cycle recovering waste heat from an exhaust gas stream. Energy Sci. Eng. 2019, 7, 230-254. [CrossRef]

7. El Hefni, B.; Bouskela, D. Boiler (Steam Generator) Modeling. In Modeling and Simulation of Thermal Power Plants with ThermoSysPro: A Theoretical Introduction and a Practical Guide; Springer International Publishing: Cham, Switzerland, 2019; pp. 153-164, ISBN 978-3-030-05105-1.

8. Sankar, G.; Kumar, D.S.; Balasubramanian, K.R. Computational modeling of pulverized coal fired boilers -A review on the current position. Fuel 2019, 236, 643-665. [CrossRef]

9. Trojan, M. Modeling of a steam boiler operation using the boiler nonlinear mathematical model. Energy 2019, 175, 1194-1208. [CrossRef] 
10. Naeimi, A.; Bidi, M.; Ahmadi, M.H.; Kumar, R.; Sadeghzadeh, M.; Alhuyi Nazari, M. Design and exergy analysis of waste heat recovery system and gas engine for power generation in Tehran cement factory. Therm. Sci. Eng. Prog. 2019, 9, 299-307. [CrossRef]

11. Barroso, J.; Barreras, F.; Amaveda, H.; Lozano, A. On the optimization of boiler efficiency using bagasse as fuel 放. Fuel 2003, 82, 1451-1463. [CrossRef]

12. Said, S.M.; Hamouda, A.S.; Mahmaoud, H.; Abd-Elwahab, S. Computer-based boiler efficiency improvement. Environ. Prog. Sustain. Energy 2019, 1-9. [CrossRef]

13. Gungor, K.E.; Winterton, R.H.S. A general correlation for flow boiling in tubes and annuli. Int. J. Heat Mass Transf. 1986, 29, 351-358. [CrossRef]

14. Kandlikar, S.G. A General Correlation for Saturated Two-Phase Flow Boiling Heat Transfer Inside Horizontal and Vertical Tubes. J. Heat Transf. 1990, 112, 219-228. [CrossRef]

15. Judd, R.L.; Hwang, K.S. A Comprehensive Model for Nucleate Pool Boiling Heat Transfer Including Microlayer Evaporation. J. Heat Transf. 1976, 98, 623-629. [CrossRef]

16. Krepper, E.; Rzehak, R. CFD for subcooled flow boiling: Simulation of DEBORA experiments. Nucl. Eng. Des. 2011, 241, 3851-3866. [CrossRef]

17. Kunkelmann, C.; Stephan, P. CFD simulation of boiling flows using the volume-of-fluid method within OpenFOAM. Numer. Heat Transf. Part A Appl. 2009, 56, 631-646. [CrossRef]

18. Zhang, X.; Yu, T.; Cong, T.; Peng, M. Effects of interaction models on upward subcooled boiling flow in annulus. Prog. Nucl. Energy 2018, 105, 61-75. [CrossRef]

19. Promtong, M.; Cheung, S.C.P.; Yeoh, G.H.; Vahaji, S.; Tu, J. CFD investigation of sub-cooled boiling flow using a mechanistic wall heat partitioning approach with Wet-Steam properties. J. Comput. Multiph. Flows 2018, 10, 239-258. [CrossRef]

20. Pothukuchi, H.; Kelm, S.; Patnaik, B.S.V.; Prasad, B.V.S.S.S.; Allelein, H.-J. Numerical investigation of subcooled flow boiling in an annulus under the influence of eccentricity. Appl. Therm. Eng. 2018, 129, 1604-1617. [CrossRef]

21. Krepper, E.; Končar, B.; Egorov, Y. CFD modelling of subcooled boiling-Concept, validation and application to fuel assembly design. Nucl. Eng. Des. 2007, 237, 716-731. [CrossRef]

22. Rivera, W.; Xicale, A. Heat transfer coefficients in two phase flow for the water/lithium bromide mixture used in solar absorption refrigeration systems. Sol. Energy Mater. Sol. Cells 2001, 70, 309-320. [CrossRef]

23. Owhaib, W.; Palm, B.; Martín-Callizo, C. Flow boiling visualization in a vertical circular minichannel at high vapor quality. Exp. Therm. Fluid Sci. 2006, 30, 755-763. [CrossRef]

24. Stevanovic, V.; Prica, S.; Maslovaric, B. Multi-Fluid Model Predictions of Gas-Liquid Two-Phase Flows in Vertical Tubes. FME Trans. 2007, 35, 173-181.

25. Yang, Z.; Peng, X.F.; Ye, P. Numerical and experimental investigation of two phase flow during boiling in a coiled tube. Int. J. Heat Mass Transf. 2008, 51, 1003-1016. [CrossRef]

26. Kouhikamali, R. Numerical simulation and parametric study of forced convective condensation in cylindrical vertical channels in multiple effect desalination systems. Desalination 2010, 254, 49-57. [CrossRef]

27. Ozawa, M.; Ami, T.; Umekawa, H.; Matsumoto, R.; Hara, T. Forced flow boiling of carbon dioxide in horizontal mini-channel. Int. J. Therm. Sci. 2011, 50, 296-308. [CrossRef]

28. Saisorn, S.; Kaew-On, J.; Wongwises, S. An experimental investigation of flow boiling heat transfer of R-134a in horizontal and vertical mini-channels. Exp. Therm. Fluid Sci. 2013, 46, 232-244. [CrossRef]

29. Shen, Z.; Yang, D.; Chen, G.; Xiao, F. Experimental investigation on heat transfer characteristics of smooth tube with downward flow. Int. J. Heat Mass Transf. 2014, 68, 669-676. [CrossRef]

30. Chen, L.; Feng, H.; Xie, Z.; Sun, F. Progress of constructal theory in China over the past decade. Int. J. Heat Mass Transf. 2019, 130, 393-419. [CrossRef]

31. Xie, Z.; Feng, H.; Chen, L.; Wu, Z. Constructal design for supercharged boiler evaporator. Int. J. Heat Mass Transf. 2019, 138, 571-579. [CrossRef]

32. Behbahaninia, A.; Ramezani, S.; Lotfi Hejrandoost, M. A loss method for exergy auditing of steam boilers. Energy 2017, 140, 253-260. [CrossRef]

33. Li, C.; Gillum, C.; Toupin, K.; Donaldson, B. Biomass boiler energy conversion system analysis with the aid of exergy-based methods. Energy Convers. Manag. 2015, 103, 665-673. [CrossRef]

34. Li, Z.; Miao, Z.; Shen, X.; Li, J. Prevention of boiler performance degradation under large primary air ratio scenario in a $660 \mathrm{MW}$ brown coal boiler. Energy 2018, 155, 474-483. [CrossRef] 
35. Li, Z.; Miao, Z.; Zhou, Y.; Wen, S.; Li, J. Influence of increased primary air ratio on boiler performance in a $660 \mathrm{MW}$ brown coal boiler. Energy 2018, 152, 804-817. [CrossRef]

36. Javan, S.; Ahmadi, P.; Mansoubi, H.; Jaafar, M.N.M. Exergoeconomic Based Optimization of a Gas Fired Steam Power Plant Using Genetic Algorithm. Heat Transf. Res. 2015, 44, 533-551. [CrossRef]

37. Pattanayak, L.; Ayyagari, S.P.K.; Sahu, J.N. Optimization of sootblowing frequency to improve boiler performance and reduce combustion pollution. Clean Technol. Environ. Policy 2015, 17, 1897-1906. [CrossRef]

38. Sobota, T. Improving Steam Boiler Operation by On-Line Monitoring of the Strength and Thermal Performance. Heat Transf. Eng. 2018, 39, 1260-1271. [CrossRef]

39. Nikula, R.-P.; Ruusunen, M.; Leiviskä, K. Data-driven framework for boiler performance monitoring. Appl. Energy 2016, 183, 1374-1388. [CrossRef]

40. Vandani, A.M.K.; Bidi, M.; Ahmadi, F. Exergy analysis and evolutionary optimization of boiler blowdown heat recovery in steam power plants. Energy Convers. Manag. 2015, 106, 1-9. [CrossRef]

41. Huang, G.; Huang, G.B.; Song, S.; You, K. Trends in extreme learning machines: A review. Neural Netw. 2015, 61, 32-48. [CrossRef]

42. Salerno, V.; Rabbeni, G. An Extreme Learning Machine Approach to Effective Energy Disaggregation. Electronics 2018, 7, 235. [CrossRef]

43. Hussain, T.; Siniscalchi, S.M.; Lee, C.C.; Wang, S.S.; Tsao, Y.; Liao, W.H. Experimental study on extreme learning machine applications for speech enhancement. IEEE Access 2017, 5, 25542-25554. [CrossRef]

44. Hinton, G.E. Training Products of Experts by Minimizing Contrastive Divergence. Neural Comput. 2002, 14, 1771-1800. [CrossRef] [PubMed]

45. Sadeghzadeh, M.; Ahmadi, M.H.; Kahani, M.; Sakhaeinia, H.; Chaji, H.; Chen, L. Smart modeling by using artificial intelligent techniques on thermal performance of flat-plate solar collector using nanofluid. Energy Sci. Eng. 2019, 1-10. [CrossRef]

46. Kahani, M.; Ahmadi, M.H.; Tatar, A.; Sadeghzadeh, M. Development of multilayer perceptron artificial neural network (MLP-ANN) and least square support vector machine (LSSVM) models to predict Nusselt number and pressure drop of $\mathrm{TiO}_{2} /$ water nanofluid flows through non-straight pathways. Numer. Heat Transf. Part A Appl. 2018, 74, 1190-1206. [CrossRef]

(C) 2019 by the authors. Licensee MDPI, Basel, Switzerland. This article is an open access article distributed under the terms and conditions of the Creative Commons Attribution (CC BY) license (http://creativecommons.org/licenses/by/4.0/). 